\title{
Quantitative detection of C-reactive protein using phosphocholine-labelled enzyme or microspheres
}

\author{
Orla Deegan, ${ }^{\mathrm{a}}$ Kieran Walshe, ${ }^{\mathrm{b}}$ Kevin Kavanagh, ${ }^{\mathrm{a}}$ and Sean Doyle ${ }^{\mathrm{a}, *}$

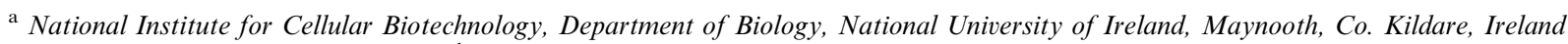 \\ ${ }^{\mathrm{b}}$ Tridelta Development Ltd., Bray, Co. Wicklow, Ireland
}

Received 8 July 2002

\begin{abstract}
C-reactive protein (CRP) is a positive, acute-phase protein. Plasma levels rise dramatically in response to tissue injury or inflammation and fall rapidly after recovery or treatment. Antibody-based human CRP test systems do not readily detect CRP from other animals due to the species specificity of antibodies directed against human CRP. Thus, generic systems for CRP detection, based solely on the interaction between CRP and phosphocholine (PC), have been developed. PC-bovine serum albumin (PC-BSA) conjugates were produced and either labeled with horseradish peroxidase to facilitate CRP detection in a CRP enzyme-linked sorbent assay (ELSA) or coupled to carboxy-modified microspheres to facilitate the nonenzymatic, turbidimetric detection of CRP. The CRP-ELSA is a competitive assay, where the total assay time is $45 \mathrm{~min}$, the assay sensitivity is $1.06 \mathrm{mg} / \mathrm{L} \mathrm{CRP}$, and the dynamic range of the assay is $0-500 \mathrm{mg} / \mathrm{L}$. When PC-BSA conjugate is covalently coupled to carboxylated microspheres, agglutination occurs in the presence of CRP, the extent of which depends on the quantity of CRP present in the sample. Total assay time is $5 \mathrm{~min}$ with a dynamic range of $25-500 \mathrm{mg} / \mathrm{L}$. Both assay formats are capable of accurately detecting human CRP and the CRP-ELSA can detect canine CRP as a disease state indicator.
\end{abstract}

() 2003 Elsevier Science (USA). All rights reserved.

Keywords: Turbidimetry; ELISA; Veterinary disease; Cardiac; Inflammation; Cancer

C-reactive protein $(\mathrm{CRP})^{1}$ is a member of a highly conserved family of proteins, the pentraxins. It is composed of five identical subunits bound noncovalently to each other in a cyclic pentameric structure [1]. In humans, CRP is a positive acute-phase protein and plasma levels of CRP elevate dramatically in response to tissue injury, infection, or inflammation from less than one to several hundred milligrams per liter [2]. Plasma CRP

\footnotetext{
${ }^{*}$ Corresponding author. Fax: +353-1-708-3845.

E-mail address: sean.doyle@may.ie (S. Doyle).

${ }^{1}$ Abbrevations used: CRP, C-reactive protein; ELISA, enzymelinked immunosorbent assay; PC, phosphocholine; PC-BSA, PCconjugated bovine serum albumin; ELSA, enzyme-linked sorbent assay; CDPC, cytidine 5'-diphosphocholine; HRP, horseradish peroxidase; SMCC, 4-(maleimidomethyl)cyclohexanecarboxylic acid $N$-hydroxysuccinimide ester; SATA, $S$-acetyl thioglycolic acid $N$ hydroxysuccinimide; MES, 2-[ $N$-morpholino]ethanesulponic acid; IT, immunoturbidimetric; EDAC, 1-ethyl-3-(3-dimethylamino-propyl) carbodiimide.
}

levels fall just as rapidly after recovery or treatment and it is now known that the half-life of plasma CRP is approximately $19 \mathrm{~h}$ [3]. Recent studies have shown that measurement of CRP levels within the normal range has significance in the risk assessment of cardiovascular disease and circulatory disorders such as peripheral vascular disease [4].

Conventional assay systems for the detection of CRP, such as immunonephelometry, immunoturbidimetry, immunoluminometry, and enzyme-linked immunosorbent assay (ELISA), all depend upon the availability of either polyclonal or monoclonal antibodies [5]. In practice, the reproducibility and cost of antibody supply are significant rate-limiting factors with respect to the reproducible and reliable manufacture of these CRP detection systems. Polyclonal antibody production is unsatisfactory for the large-scale production of antibody reagent due to the variability in immune response in different animals which can result in the production of antibody preparations of variable specificity and sensi- 
tivity of detection [6,7]. Furthermore, species-specific CRP test systems do not readily detect CRP from unrelated species due to the absence of common antigenic sites [8]. This factor is of significant concern from the viewpoint of animal welfare, whereby a generic CRP detection system for veterinary specimens would greatly facilitate improvement both in the diagnosis of animal disease and in animal husbandry methods. The requirement therefore exists for a nonimmunological test system for the multispecies detection of CRP to overcome the aforementioned limitations.

Calcium-mediated CRP binding to immobilized phosphocholine (PC) in association with enzyme-labeled antibody detection of captured CRP, has been proposed as an alternative CRP detection methodology $[9,10]$. Both of these assays involve coating microwells with PC-conjugated bovine serum albumin (PC-BSA) followed by the addition of CRP. The quantity of CRP is then immunometrically determined by indirect ELISA using goat IgG [anti-CRP] followed by a commercial rabbit anti-species IgG-alkaline phosphate conjugate [9] or rabbit IgG [anti-CRP] followed by the addition of enzyme-labeled donkey anti-rabbit IgG [11]. The precision of the latter assay was found to be $12.3 \pm 5.3 \% \mathrm{CV}$ (percentage coefficient of variation) over a range of CRP concentrations, while the sensitivity of detection was observed to be $2.5 \mathrm{mg} / \mathrm{L}$ CRP. More recently, another test system exploiting CRP/PC interaction has been described [12]: however, this test requires extensive signal amplification techniques such as fluorometric or radioactive detection of $\mathrm{CRP} / \mathrm{PC}$ complex and antibodymediated immobilization of the target CRP analyte as in the aforementioned methods.

In the present study we undertook the development of (i) an entirely nonimmunological assay (enzymelinked sorbent assay (ELSA)) for CRP detection based solely on the calcium-dependent binding affinity of CRP for phosphocholine and (ii) a turbidimetric assay for the detection of CRP based on latex microsphere-labeled PC-BSA, thereby eliminating the requirement for enzymatic detection and multiple wash steps.

\section{Materials and methods}

\section{Materials}

All materials were obtained from Sigma-Aldrich Chemical Company (Dorset, UK) unless otherwise indicated.

\section{Conjugation of phosphocholine to bovine serum albumin}

All manipulations were carried out at room temperature and were performed essentially as previously described [10]. Briefly, cytidine 5'-diphosphocholine
(CDPC) was subjected to periodate oxidation and added

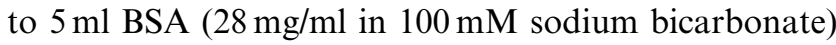
$(n=3)$ at (A) 70-, (B) 7-, and (C) 0.7-fold molar excess. Stable Schiff bond formation occurred by subsequent addition of $5 \mathrm{ml} 500 \mathrm{mM}$ sodium borohydride to each of preparations A-C. Following PC-BSA conjugation, the reaction mixture was dialyzed exhaustively at $4{ }^{\circ} \mathrm{C}$ in either $50 \mathrm{mM}$ potassium phosphate, $1 \mathrm{mM}$ EDTA, $150 \mathrm{mM}$ $\mathrm{NaCl}, \mathrm{pH} 7.8$, or $100 \mathrm{mM}$ sodium borate, $\mathrm{pH} 8.5$, and then stored at $-20^{\circ} \mathrm{C}$ until used for conjugation to horseradish peroxidase (HRP) or coupling to microspheres.

\section{Conjugation of HRP and PC-BSA}

PC-BSA preparations $(\mathrm{A}-\mathrm{C})$ were each modified at $1 \mathrm{mg} / \mathrm{ml}$ with 4-(maleimidomethyl)cyclohexanecarboxylic acid $N$-hydroxysuccinimide ester (SMCC) by adding $7.5 \mu 125 \mathrm{mM}$ SMCC in dimethylformamide per $1 \mathrm{ml}$ PC-BSA solution and incubating at room temperature for $30 \mathrm{~min}$. SMCC-activated PC-BSA (PC-BSA-SM CC) preparations were dialyzed against $50 \mathrm{mM}$ potassium phosphate, $1 \mathrm{mM}$ EDTA, $150 \mathrm{mM}$ sodium chloride, pH 6.8. $S$-acetyl thioglycolic acid $N$-hydroxy- succinimide (SATA) was used to activate HRP as previously described [13] and deblocked by the addition of $500 \mathrm{mM}$ hydroxylamine (1/10 volume of SATA-HRP solution). PC-BSA-SMCC preparations were added to three separate tubes containing deblocked HRP in the ratio of $1 \mathrm{mg}$ PC-BSA-SMCC per $4.6 \mathrm{mg}$ SATA-HRP, further incubated for $5 \mathrm{~h}$ at room temperature, and dialyzed against phosphate-buffered saline. PC-BSA-HRP conjugate formation was confirmed by functionality testing.

\section{CRP-ELSA assay format}

Human CRP standards (range $0-10 \mathrm{mg} / \mathrm{L}$ ) were prepared by diluting a stock solution of CRP $(24 \mathrm{mg} / \mathrm{ml})$ in $50 \mathrm{mM}$ 2-( $N$-morpholino)ethanesulfonic acid (MES), $25 \mathrm{mM}$ sodium chloride, $10 \mathrm{mM}$ calcium chloride, and $0.1 \%(\mathrm{v} / \mathrm{v})$ Tween 20, pH 6.0. PC-BSA-HRP conjugate (1/8000 dilution) and specimens for analysis were also diluted in this buffer. Next, $50 \mu$ of standards or specimens and $50 \mu \mathrm{l}$ of the conjugate were added into microwells previously coated with human CRP (100 ng/ well human CRP) (Fig. 1A). After incubation at room temperature for $30 \mathrm{~min}$, the microwells are washed four times with $50 \mathrm{mM}$ Tris- $\mathrm{HCl}, 25 \mathrm{mM}$ sodium chloride, $10 \mathrm{mM}$ calcium chloride, $0.1 \%$ (v/v) Tween 20, pH 7.4. Tetramethylbenzidine $(2.08 \mathrm{mM} ; 100 \mu \mathrm{l})$ was added per well followed by a 15-min incubation (Fig. 1A). The reaction was stopped by adding $100 \mu \mathrm{l} 1 \mathrm{~N} \mathrm{H}_{2} \mathrm{SO}_{4}$ and the absorbance was read at $450 / 630 \mathrm{~nm}$ followed by calculation of specimen [CRP] from the standard curve. This CRP-ELSA was validated with regard to assay parameters (time, temperature, buffer conditions), assay 

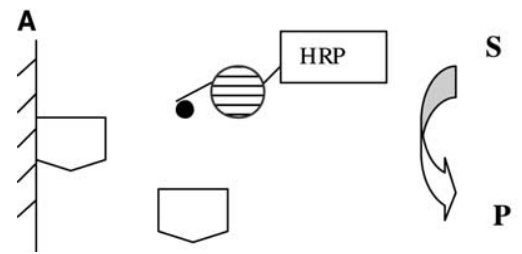

B

Fig. 1. (A) Schematic representation of C-reactive protein-enzyme linked sorbent assay. Phosphocholine (black circle)-bovine serum albumin (hashed circle)-horseradish peroxidase conjugate (PC-BSA-HRP) is added simultaneously with free CRP (pentagon) to microwells precoated with CRP. Free CRP competes with immobilized CRP for binding to PC-BSA-HRP conjugate. Substrate (S; tetramethylbenzidine) is then added and product (P) formation, measured spectrophotometrically at $450 / 630 \mathrm{~nm}$, is inversely proportional to CRP concentration. (B) Turbidimetric-CRP assay system. Immobilized PC (black circles) on latex particles (shaded circle) bind free CRP (pentagon) in solution (indicated by dashed lines) to form an insoluble complex. The extent of complex formation, measured spectrophotometrically at $550 \mathrm{~nm}$, is proportional to CRP concentration.

sensitivity and reproducibility, linearity of dilution, and multispecies CRP detection.

\section{Covalent coupling of PC-BSA to carboxy-modified microparticles}

Carboxy-modified microspheres $(0.21 \mu \mathrm{M}$ diameter; $10 \%(\mathrm{w} / \mathrm{v}) ; 100 \mu \mathrm{l})$, obtained from Bangs Laboratories (Fishers, IN), were activated following addition of $100 \mu \mathrm{l} 500 \mathrm{mM}$ MES, pH 6.1, $500 \mu \mathrm{l}$, deionized water, $230 \mu \mathrm{l}$ sulfo $N$-hydroxysulfosuccinamide $(50 \mathrm{mg} / \mathrm{ml})$, and $24 \mu \mathrm{l}$ 1-ethyl-3-(3-dimethylaminopropyl)carbodiimide $(10 \mathrm{mg} / \mathrm{ml})$ for $30 \mathrm{~min}$. Following centrifugation $(10,000 \mathrm{~g}$ for $20 \mathrm{~min})$, microspheres were twice resuspended by sonication in $1 \mathrm{ml} 50 \mathrm{mM}$ MES, pH 6.1. Finally, the microspheres were resuspended by sonication in $1 \mathrm{ml}$ of PC-BSA protein stock $(1 \mathrm{mg} / \mathrm{ml})$ in $100 \mathrm{mM}$ sodium borate, $\mathrm{pH} 8.5$, and mixed at room temperature for $1 \mathrm{~h}$. Then, $250 \mathrm{mM}$ ethanolamine hydrochloride in $100 \mathrm{mM}$ sodium borate, $\mathrm{pH} 8.5(50 \mu \mathrm{l})$, was added followed by centrifugation as above and microspheres resuspension in $1 \mathrm{ml}$ of $10 \mathrm{mg} / \mathrm{ml} \mathrm{BSA}$ in $100 \mathrm{mM}$ sodium borate, $\mathrm{pH}$ 8.5. Finally, the microspheres $(1 \%(\mathrm{w} / \mathrm{v})$ suspension) were washed twice, resuspended in $1 \mathrm{ml}$ of $50 \mathrm{mM}$ Tris- $\mathrm{HCl}, 25 \mathrm{mM}$ sodium chloride, $10 \mathrm{mM}$ calcium chloride, $\mathrm{pH} 7.4$, with sonication, and stored at $4^{\circ} \mathrm{C}$ until required for use.

\section{Turbidimetric assay format}

Prior to specimen addition, PC-BSA-coated microspheres were diluted to $0.03 \%(\mathrm{w} / \mathrm{v})$ in microsphere diluent comprising $0.4 \%$ (w/v) PEG 6000 in $100 \mathrm{mM}$ glycine, $90 \mathrm{mM}$ sodium chloride, $10 \mathrm{mM}$ calcium chloride, $0.04 \%(\mathrm{w} / \mathrm{v})$ sodium azide, $\mathrm{pH} 7.6$, to give "working reagent." Working reagent, standards, and specimens were loaded onto a Cobos Mira autoanalyzer (Roche Diagnostics, Rotkreuz, Switzerland) programed to dispense either standards or specimens (10 $\mu \mathrm{l}$ each) along with working reagent $(490 \mu \mathrm{l})$ into reaction cuvettes and brought to $37^{\circ} \mathrm{C}$ (Fig. 1B). The reaction was initiated by addition of the working reagent and allowed to proceed at $37^{\circ} \mathrm{C}$ for $5 \mathrm{~min}$. The absorbance $(550 \mathrm{~nm})$ of all standards and specimens was determined at $T=0$ and at $T=5 \mathrm{~min}$ after which time it was observed that PC-CRP binding was complete (data not shown). Upon completion of the analysis, the change in absorbance $(\Delta \mathrm{A})$ value for each standard and specimen was computed and specimen CRP concentrations were calculated from a plot of $\Delta \mathrm{A}_{550 \mathrm{~nm}}$ (standards) versus [CRP] $(\mathrm{mg} / \mathrm{L})$. The turbidimetric-CRP (t-CRP) assay was validated with regard to assay parameters (time, temperature, buffer conditions), National Institute for Biological Standards and Control (Hertfordshire, UK) human C-reactive protein (1st International Standard; Code 85/506) detection, assay sensitivity, and linearity of dilution.

\section{Results}

\section{Preparation of $P C-B S A-H R P$ conjugates}

Following modification of BSA at (A) 70-, (B) 7-, and (C) 0.7-fold molar excess of CDPC, preparations were further activated by SMCC prior to HRP conjugation. Analysis of PC-BSA confirmed the presence of 0.7, 3.7, and 3.2 maleimide groups for preparations $\mathrm{A}, \mathrm{B}$, and $\mathrm{C}$, respectively. Subsequent to HRP conjugation, no evidence of high-molecular-weight PC-BSA-HRP conjugate formation was observed by either SDS-PAGE or Western blot analysis using IgG (anti-bovine serum albumin) (data not shown). Therefore, in the absence of conjugate visualization, extensive functional testing was undertaken to confirm conjugate formation.

The successful formation of functional PC-BSAHRP conjugates was confirmed using the ELSA assay format except that microwells were precoated with either CRP $(1$ or $10 \mu \mathrm{g} / \mathrm{ml})$ or BSA $(1 \mu \mathrm{g} / \mathrm{ml})$. In the absence of purified CRP, the PC-BSA-HRP conjugate bound to the CRP-coated microwells, however, when CRP was present in the specimen, even at concentrations as low as $0.1 \mathrm{mg} / \mathrm{L}$, the absorbance decreased with increasing concentrations of CRP (Fig. 2A). The optimal PC-BSA-HRP conjugate (CM-3A), formed following activation at a 70 -fold molar excess of CDPC, 

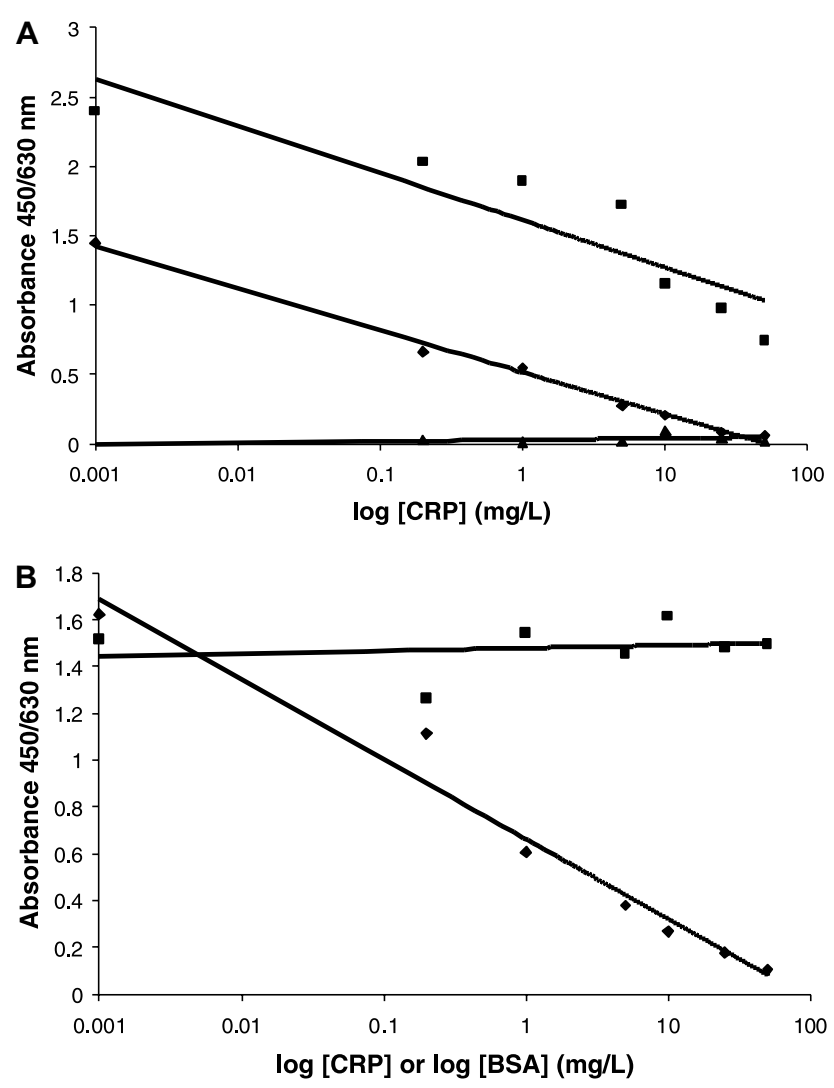

Fig. 2. (A) Plot of absorbance $450 / 630 \mathrm{~nm}$ versus $\log [\mathrm{CRP}](\mathrm{mg} / \mathrm{L})$ to evaluate the functionality and specificity of PC-BSA-HRP conjugate (CM-3A) for CRP. Microwells were coated with either $1 \mu \mathrm{g} \mathrm{CRP} \mathrm{( \square ),}$ $100 \mathrm{ng}$ CRP $(\diamond)$, or $100 \mathrm{ng}$ BSA $(\boldsymbol{\Delta})$. CM-3A binding is evident for CRP-coated microwells only and no conjugate binding to BSA-coated microwells is observed. (B) Plot of absorbance $450 / 630 \mathrm{~nm}$ versus $\log$ [CRP] $(\bullet)$ or $\log [\mathrm{BSA}](\mathrm{mg} / \mathrm{L})(\mathbf{\square})$ at a microwell coating level of $100 \mathrm{ng}$ CRP. Binding of conjugate CM-3A to CRP is not inhibited in the presence of a nonspecific protein (BSA).

did not exhibit any affinity for the BSA-coated microwells, thereby confirming the specificity of the conjugate for CRP (Fig. 2A). Further evidence in support of the specific detection of CRP by conjugate CM-3A is shown in Fig. 2B. Here, standards of either BSA or CRP were prepared $(0-50 \mathrm{mg} / \mathrm{L})$ and added to CRP-coated plates $(1 \mu \mathrm{g} / \mathrm{ml})$ using the CM-3A conjugate for the detection of CRP. The presence of BSA did not cause any significant decrease in absorbance, thus confirming that the CM-3A conjugate could determine the presence of specimen CRP, while the presence of nonspecific protein (BSA) did not inhibit the binding of the CM-3A conjugate to the immobilized CRP. All subsequent microwell assays were carried out using conjugate CM-3A.

\section{CRP-ELSA}

The dynamic range of the assay was $0-10 \mathrm{mg} / \mathrm{L}$ human CRP, which represents $0-500 \mathrm{mg} / \mathrm{L}$ CRP in specimens diluted $1 / 50$ and subsequently tested in the
CRP-ELSA. Fig. 3 illustrates a typical standard curve for the CRP-ELSA from which either human serum or plasma CRP levels can be determined.

ELSA sensitivity of detection was $1.06 \mathrm{mg} / \mathrm{L} \mathrm{CRP}$, as calculated from the mean +2 standard deviations when individual human plasma specimens, deficient in CRP, were assayed $(n=20)$, and is within normal CRP levels in human plasma $(0-6 \mathrm{mg} / \mathrm{L})$. CRP-ELSA reproducibility was $5.5 \% \mathrm{CV}$ at $6.25 \mathrm{mg} / \mathrm{L}(n=12), 7.6 \% \mathrm{CV}$ at $50 \mathrm{mg} / \mathrm{L}(n=12)$, and $14.0 \% \mathrm{CV}$ at $500 \mathrm{mg} / \mathrm{L}(n=12)$. Following determination of CRP levels in human serum specimens $(n=28)$ assayed at dilutions of $1 / 50$ and $1 / 300$, results were plotted against the CRP concentrations (range: $14.3-279 \mathrm{mg} / \mathrm{L}$ ) determined for identical specimens by immunoturbidimetric (IT) assay (Dade Behring, Newark, DE). The correlation coefficients calculated by comparing both data sets were 0.93 for specimens diluted at $1 / 50$ and 0.94 for samples diluted at $1 / 300$ in $50 \mathrm{mM}$ MES, $10 \mathrm{mM}$ calcium chloride, $25 \mathrm{mM}$ sodium chloride, $0.1 \%$ (v/v) Tween 20, pH 6.0 (Fig. 4). These human plasma specimens were also assayed in identical buffers containing either $50 \mathrm{mM}$ Tris- $\mathrm{HCl}, \mathrm{pH}$ 7.4 , or $50 \mathrm{mM}$ sodium phosphate, $\mathrm{pH} 5.0$, instead of $50 \mathrm{mM}$ MES $\mathrm{pH}$ 6.0. Although the alteration in diluent $\mathrm{pH}$ had minimal effect on standard CRP detection, specimen correlation coefficients against IT CRP data were 0.79 and 0.85 in $50 \mathrm{mM}$ Tris- $\mathrm{HCl}, \mathrm{pH} \mathrm{7.4}$, and $50 \mathrm{mM}$ sodium phosphate, $\mathrm{pH} 5.0$, respectively, indicating that optimal specimen CRP detection occurs at pH 6.0.

Increasing the reaction temperature to $37^{\circ} \mathrm{C}$ from $20^{\circ} \mathrm{C}$ did not cause a significant improvement in assay sensitivity (data not shown). Furthermore, while $15 \mathrm{~min}$ incubation time did not facilitate optimal binding of

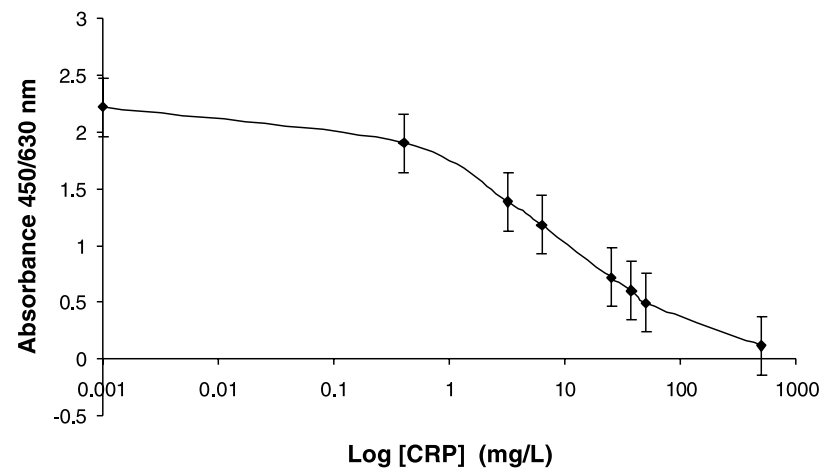

Fig. 3. Plot of absorbance $450 / 630 \mathrm{~nm}$ versus $\log [\mathrm{CRP}](\mathrm{mg} / \mathrm{L})$ to illustrate the CRP-ELSA standard curve (sigmoidal type) for human CRP standards prepared in optimized assay diluent; $50 \mathrm{mM}$ Mes, $25 \mathrm{mM}$ sodium chloride, $10 \mathrm{mM}$ calcium chloride, $0.1 \%$ (v/v) Tween 20 , $\mathrm{pH}$ 6.0. Standards were assayed in duplicate and data points are given as mean \pm standard error. PC-BSA-HRP conjugate was also prepared in this diluent and immediately added to CRP-coated microwells after standard or specimen CRP addition. The assay was allowed to proceed for $30 \mathrm{~min}$ prior to a wash step and tetramethylbenzidine substrate addition. 


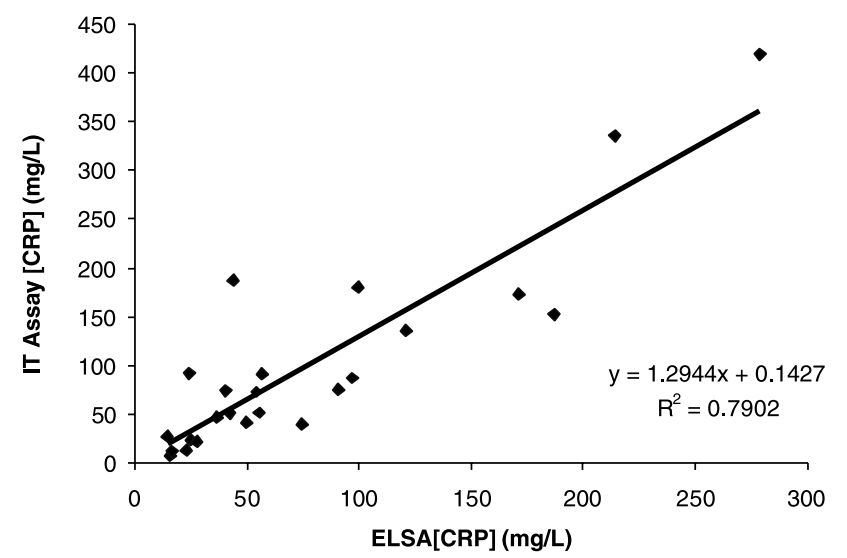

Fig. 4. Linear regression analysis of human $[\mathrm{CRP}](\mathrm{mg} / \mathrm{L})$ determined by conventional immunoturbidimetric assay (IT assay) and CRPELSA methodology. Specimens were diluted at 1/50 and assayed as described under Materials and methods, and the correlation coefficient was calculated to be 0.93 .

CRP either to the PC-BSA-HRP conjugate or to the CRP-coated microwells, an incubation time of $30 \mathrm{~min}$ was sufficient as there was no significant increase in CRP binding between 30 and $60 \mathrm{~min}$ incubation (data not shown). Calcium ion presence was found to be essential for PC/CRP binding and it was found that $10 \mathrm{mM}$ calcium chloride facilitated optimal interaction. Under these CRP-ELSA conditions, the PC/CRP interaction was decreased by approximately 20 to $35 \%$, at CRP concentrations less than $1 \mathrm{mg} / \mathrm{L}$, if the assay diluent was modified to contain 150 or $300 \mathrm{mM}$ sodium chloride, thus indicating that positive ions may interfere with the calcium-mediated interaction between CRP and PC.

Detection of CRP in canine sera confirms that the CRP-ELSA is compatible with specimens of nonhuman origin. Following CRP-ELSA analysis, using purified human CRP as standard, alterations in canine serum CRP levels were detectable postsurgery whereby both elevation and diminution in canine CRP levels were measurable. Specifically, a 10 -fold increase in serum CRP was detectable within $24 \mathrm{~h}$ of cruciate ligament surgery while reduction in CRP level to $33.6 \mathrm{mg} / \mathrm{L}$ is also clearly measurable (Fig. 5A). Confirmation that CRP of nonhuman (canine) origin is detectable is seen also in Fig. 5B where a correlation coefficient of 0.89 is observed following comparison of specimen CRP concentrations from 10 to $200 \mathrm{mg} / \mathrm{L}(n=14)$ determined by CRP-ELSA (specimen dilution of $1 / 10$ ) and an $\operatorname{IgG}$ [anti-canine CRP]-HRP enzyme immunoassay (Canine CRP ELISA (Tridelta, Wicklow, Ireland); Product code: TP803). Significantly, a near-identical correlation coefficient of 0.88 is observed at specimen dilution of $1 / 50$, confirming linearity of dilution for canine CRP detection.
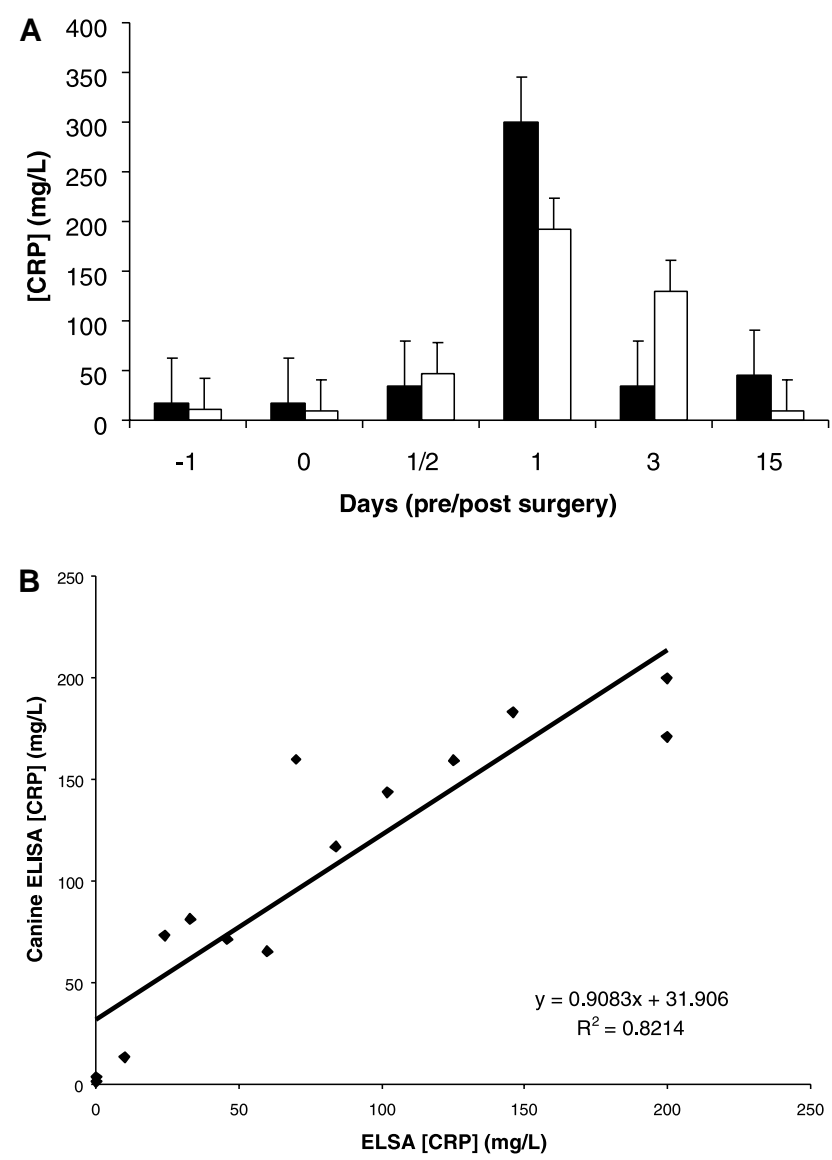

Fig. 5. (A) Determination of [CRP] $(\mathrm{mg} / \mathrm{L})$ in canine sera. These data illustrate the change in CRP levels in canine sera obtained pre- and postcruciate ligament surgery, from a single animal, as measured by CRP-ELSA (black bars) and by a commercially available CRP-ELISA system (white bars). All specimens were assayed in duplicate using human CRP as standard material and data are given as mean + standard error. (B) Linear regression analysis for canine CRP analyzed by a commercially available CRP-ELISA and by CRP-ELSA. Specimens were diluted at $1 / 10$ prior to CRP-ELSA analysis and the correlation coefficient was calculated to be 0.89 .

\section{Turbidimetric detection of C-reactive protein}

Evaluation of the PC-BSA coupling concentration between 0.4 and $1.6 \mathrm{mg} / \mathrm{ml}$ showed that $1 \mathrm{mg}$ PC-BSA per $10 \mathrm{mg}$ EDAC-activated microspheres gave optimal assay performance (data not shown). A typical t-CRP calibration curve is shown in Fig. 6. The t-CRP assay exhibits an assay range of $0.5-10 \mathrm{mg} / \mathrm{L}$, which equates to a specimen CRP concentration range of $25-500 \mathrm{mg} / \mathrm{L}$, assuming a $1 / 50$ specimen dilution. t-CRP assay reproducibility is $6.3 \% \mathrm{CV}$ at $250 \mathrm{mg} / \mathrm{L}(n=24), 8.4 \% \mathrm{CV}$ at $100 \mathrm{mg} / \mathrm{L}(n=24)$, and $15.6 \%$ at $50 \mathrm{mg} / \mathrm{L}(n=24)$. A significant correlation (Spearman correlation coefficient $=0.78 ; p<0.0001$ ) was observed following the evaluation of CRP levels (range: $25-361.9 \mathrm{mg} / \mathrm{L}$ ) in human plasma specimens $(n=28)$ by the t-CRP assay and a commercial IT assay (Tina-quant CRP, Roche 


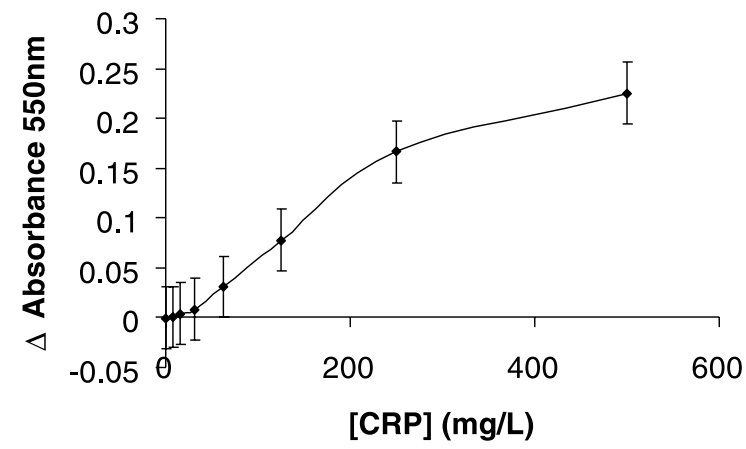

Fig. 6. Plot of $\Delta$ absorbance $550 \mathrm{~nm}$ versus [CRP] (mg/L) following turbidimetric analysis of purified human CRP. Standards were assayed in duplicate and data points are given as mean \pm standard error. The assay was performed by adding $10 \mu \mathrm{l}$ standards or specimens to $490 \mu \mathrm{l}$ PC-labeled microspheres $(0.03 \%(w / v))$ in reaction cuvettes and allowed to proceed at $37^{\circ} \mathrm{C}$ for $5 \mathrm{~min}$ after which time the $\Delta$ absorbance at $550 \mathrm{~nm}$ was computed. The "in tube" assay range is $0.5-10 \mathrm{mg} / \mathrm{L}$, which equates to a specimen CRP concentration range of $25-500 \mathrm{mg} / \mathrm{L}$ (1/50 specimen dilution).

Diagnostics, Mannheim, Germany). When known amounts of purified human CRP $(100,200,400 \mu \mathrm{g})$ were added to CRP-deficient human plasma from a single individual, a mean recovery of $99.7 \%$ was observed (range: $90.7-112 \%$ ), whereby $96.5,181.5$, and $449 \mathrm{mg} / \mathrm{L}$ CRP, respectively, was measurable. Furthermore, following evaluation of NIBSC human CRP (1st International Standard, $50 \mathrm{mg} / \mathrm{L})$, a mean ( \pm standard deviation) recovery of $52 \pm 2.19 \mathrm{mg} / \mathrm{L}(104 \% ; n=6)$ was observed, indicating both t-CRP assay compatibility with serum CRP and calibration accuracy.

\section{Discussion}

Here we describe two nonimmunological test systems for the quantitative detection of C-reactive protein. While both systems are dependent upon the calciummediated interaction between PC and CRP, interaction detection is by enzyme- or microsphere-labeled PC followed by spectrophotometric or turbidimetric assessment of PC/CRP binding, respectively.

Cytidine $5^{\prime}$-diphosphocholine was initially activated by periodate oxidation and conjugated to bovine serum albumin by Schiff base formation [10] to produce phosphocholinated-bovine serum albumin for subsequent enzyme (HRP) or microsphere (carboxy-modified) attachment. Interestingly, BSA activated in this manner could not be detected by SDS-PAGE, Western blot analysis using IgG [anti-BSA], or silver staining either because of reduced affinity for Coomassie brilliant blue $\mathrm{R}$ dye or because of epitope disruption. Nonetheless, following introduction of maleimide groups (0.7-3.7 per PC-BSA molecule), modified PC-BSA was capable of conjugation to SATA-modified HRP by thioether bond formation to form PC-BSA-HRP conjugates. Although these conjugates were capable of detecting bound CRP following attachment to immobilized PC-BSA (data not shown), the low sensitivity of detection $(100 \mathrm{mg} / \mathrm{L})$ was insufficient to facilitate robust assay development. For this reason, the development of a competitive CRP-enzyme-linked sorbent assay was undertaken whereby immobilized and free specimen/ standard CRP competed for solution-phase PC-BSAHRP conjugate.

CRP-ELSA sensitivity of detection $(1.06 \mathrm{mg} / \mathrm{L})$ compares favorably with standard automated methods for CRP quantification which generally exhibit detection limits of $3-8 \mathrm{mg} / \mathrm{L}$ [5]. It should be noted that the observed correlation coefficient $(r=0.94)$ between human CRP levels simultaneously measured by CRP-ELSA and immunoturbidimetry is superior to those previously achieved $(r=0.88)$ for the comparative study of canine CRP detection by two immunometric methods, namely ELISA and canine CRP-specific immunoturbidimetry [14]. Furthermore, in the present study, the determination of canine CRP levels by CRP-ELSA correlates closely $(r=0.89)$ with those obtained by canine CRPspecific ELISA. The CRP-ELSA dynamic range of 0-500 mg/L, along with the observed multispecies CRP detection capability, thus represents an improvement over these conventional CRP assay formats.

To our knowledge, the turbidimetric-CRP assay described here is the first single-step, nonimmunological CRP test system. Specimen CRP and microsphere-PC interaction is complete within $5 \mathrm{~min}$ and no further change in absorbance is observed even when the reaction is allowed to proceed for up to $10 \mathrm{~min}$. The t-CRP assay exhibits a broad dynamic range of $25-500 \mathrm{mg} / \mathrm{L}$ CRP and assay performance parameters - with regard to recovery and linearity of dilution - comparable with all immunoturbidimetric assay systems, and it requires no specimen pretreatment. Although the t-CRP limit of detection $(25 \mathrm{mg} / \mathrm{L})$ is above the upper limit of normal for human plasma CRP $(0-6 \mathrm{mg} / \mathrm{L})$, it is comparable with the detection limit of rapid immunological methods for CRP detection. For instance, a detection limit of $12 \mathrm{mg} / \mathrm{L}$ CRP has been described for a card-based sandwich immunoassay utilizing gold-conjugated IgG [anti-CRP] [15]. Assessment of PC-BSA-microsphere stability indicates reagent stability for at least 1 month following storage at 4 and $37^{\circ} \mathrm{C}$ and it is likely that the $4{ }^{\circ} \mathrm{C}$ stability will extend based on the $37^{\circ} \mathrm{C}$ stability data. The t-CRP assay can also be carried out using laboratory-based spectrophotometers (data not shown). To date, no plasma components which interfere with CRP-ELSA or t-CRP performance have been detected; however, further studies to confirm this observation will be required.

In summary, two nonimmunological assay systems for the detection of CRP based solely upon the 
calcium-dependent interaction between CRP and phosphocholine (International Patent Application No. PCT/IE 01/124) have been developed. The microwellbased assay (CRP-ELSA) exhibits a detection limit of $1.06 \mathrm{mg} / \mathrm{L}$, can be completed in $60 \mathrm{~min}$ and facilitates multispecies CRP detection. The turbidimetric (t-CRP) assay utilizes PC-BSA-coated microspheres, the total assay time is $5 \mathrm{~min}$ per specimen, and the assay is automatable and facilitates human CRP detection between 25 and $500 \mathrm{mg} / \mathrm{L}$.

\section{Acknowledgments}

This work was supported by Enterprise Ireland and Tridelta Development through the Innovation Partnership (IP/01/020) and the Irish American Partnership grant programs.

\section{References}

[1] D. Thompson, M.B. Pepys, S.P. Wood, The physiological structure of human C-Reactive protein and its complex with phosphocholine, Structure 7 (1999) 169-177.

[2] H.L. Johnson, C.C. Chiou, C.T. Cho, Applications of acute phase reactants in infectious diseases, J. Microbiol. Immunol. Infect. 32 (2) (1999).

[3] C. Mold, H. Gewurz, T.W. Du Clos, Regulation of complement activation by C-reactive protein, Immunopharmacology 42 (1999) $23-30$.

[4] F.C. de Beer, C.R. Hind, K.M. Fox, R.M. Allan, A. Maseri, M.B. Pepys, Measurement of serum C-reactive protein concentration in myocardial ischaemia and infarction, Br. Heart J. 47 (3) (1982) 239-243.
[5] W.L. Roberts, L. Moulton, T.C. Law, G. Farrow, M. CooperAnderson, J. Savory, N. Rifai, Evaluation of nine automated high-sensitivity C-reactive protein methods: implications for clinical and epidemiological applications. Part 2, Clin. Chem. 47 (3) (2001) 418-425.

[6] S. Yamamoto, K. Tagata, Y. Ishikawa, H. Santsuka, M. Yamada, M. Morimatsu, M. Naiki, Avidity of antibody and agglutinability of antibody-sensitized latex in latex agglutination test, Vet. Immunol. Immunopathol. 36 (3) (1993) 257-264.

[7] L.K. Dajani, E. Paus, D.J. Warren, Development of a rapid and sensitive immunofluorometric assay for Glutathione S-transferase A, Clin. Chem. 47 (5) (2001) 867-873.

[8] S. Yamamoto, S. Miyaji, N. Abe, K. Otabe, E. Furukawa, M. Naiki, Canine C-reactive protein (CRP) does not share common antigenicity with human CRP, Vet. Res. Commun. 17 (4) (1993) 259-266.

[9] T. Tanaka, F.A. Robey, A new sensitive assay for the calciumdependent binding of C-Reactive protein to phosphorylcholine, J. Immunol. Methods 65 (1983) 333-341.

[10] P.D. Eckersall, J.G. Conner, H. Parton, Conjugation of cytidine 5 diphosphocholine to bovine serum albumin in the development of an enzyme linked immunosorbent assay for canine C-reactive protein, Biochem. Soc. Trans. 414 (1989).

[11] P.D. Eckersall, J.G. Conner, H. Parton, An enzyme-linked immunosorbent assay for canine C-reactive protein, Vet. Rec. 124 (1989) 490-491.

[12] Tamura, H., Lee, Y.C., Kawaguchi, K., Takagahara, I., Matuo, Y., Saito, K., 2000. Methods for assaying CRP with the use of phosphocholine. European Patent Application EP1076240A1.

[13] R.J. Duncan, P.D. Weston, R. Wrigglesworth, A new reagent which may be used to introduce sulfhydryl groups into proteins, and its use in the preparation of conjugates for immunoassay, Anal. Biochem. 132 (1) (1983) 68-73.

[14] P.D. Eckersall, J.G. Conner, J. Harvie, An immunoturbidimertic assay for canine C-reactive protein, Vet. Res. Commun. 15 (1) (1991) 17-24

[15] P. Urdal, S.M. Borch, S. Landaas, M.B. Krutnes, G.O. Gogstad, P. Hjortdahl, Rapid immunometric measurement of C-reactive protein in whole blood, Clin. Chem. 38 (1992) 580-584. 